This item was submitted to Loughborough's Research Repository by the author.

Items in Figshare are protected by copyright, with all rights reserved, unless otherwise indicated.

\title{
Modelling, simulation and process design of the filter cycle
}

PLEASE CITE THE PUBLISHED VERSION

PUBLISHER

(C) Elsevier

VERSION

AM (Accepted Manuscript)

LICENCE

CC BY-NC-ND 4.0

REPOSITORY RECORD

Wakeman, Richard J., and E.S. Tarleton. 2009. "Modelling, Simulation and Process Design of the Filter Cycle". figshare. https://hdl.handle.net/2134/5020. 
This item was submitted to Loughborough's Institutional Repository (https://dspace.lboro.ac.uk/) by the author and is made available under the following Creative Commons Licence conditions.

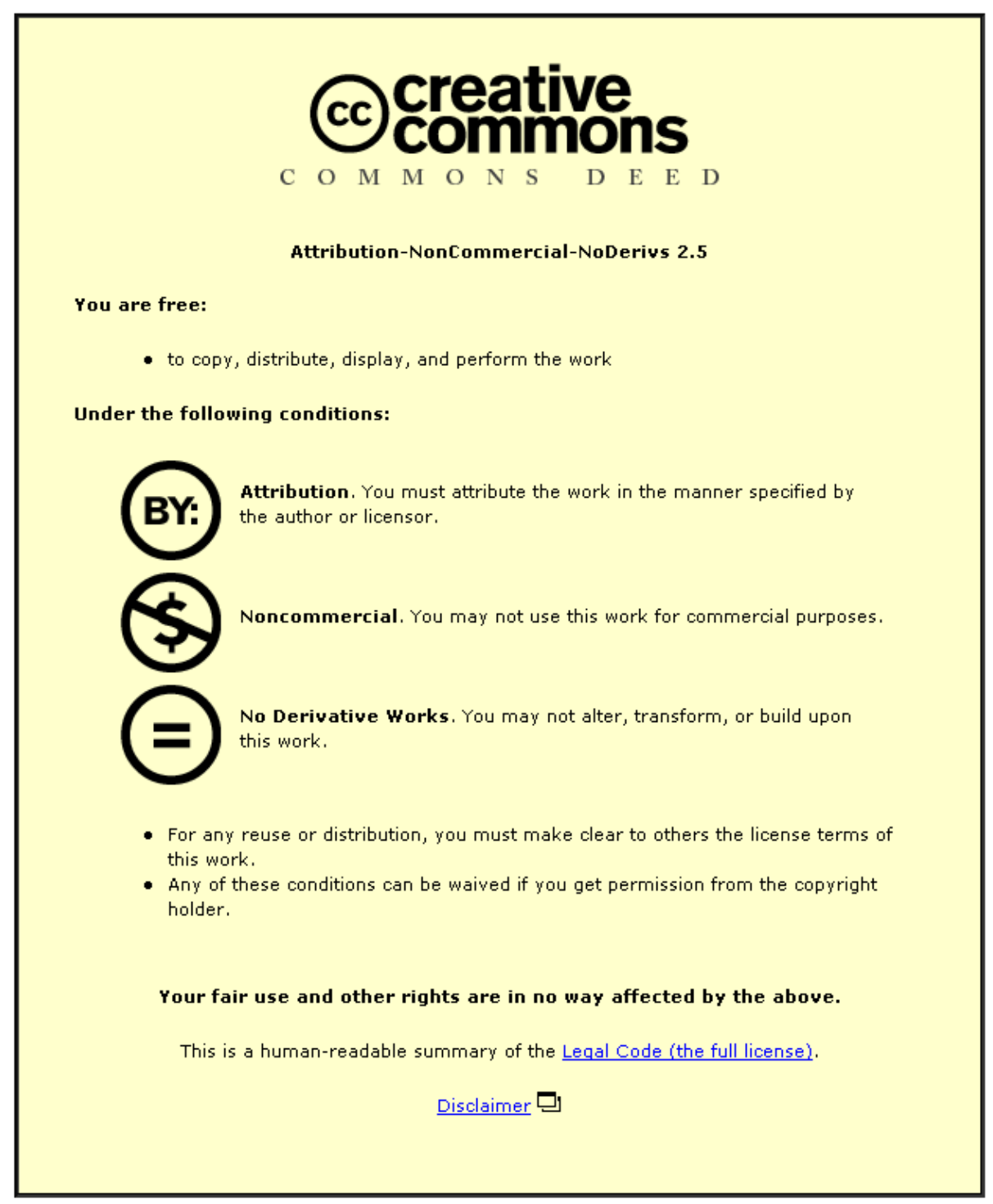

For the full text of this licence, please go to: http://creativecommons.org/licenses/by-nc-nd/2.5/ 


\title{
MODELLING, SIMULATION AND PROCESS DESIGN OF THE FILTER CYCLE
}

\author{
R.J. Wakeman and E.S. Tarleton (e.s.tarleton@lboro.ac.uk) \\ Separation Processes Centre, University of Exeter, UK.
}

\begin{abstract}
Taking a vacuum belt filter as a basis, the authors show how different stages of solid-liquid separation interact and affect one another in an attempt to point a way towards more rational design of a separation system. The models used are based on fundamental concepts of varying complexity, and sufficiently developed to facilitate design calculations. They can also be readily incorporated into process integration and optimisation packages, and form part of a suite of computer software packages being developed at Exeter University.
\end{abstract}

\section{INTRODUCTION}

Practitioners of solid/liquid separation are familiar with the fact that changes in particle production conditions can alter drastically the performance of the filter or separator and can change the economics and viability of the process. In spite of this the design of a separation system is still generally carried out in piecemeal fashion and the impact of pretreatment processes on the separation and post-treatment operations is not quantified. Indeed, the state of process modelling is such that not all aspects are quantifiable. Nevertheless, progress has been made in that direction in recent years and the purpose of this paper is to show how different stages of solid/liquid separation interact and affect one another. For the purpose of example, a vacuum belt filter is considered, with options to perform any combination of the operations shown in Figure 1.

The simplest sequence of filter operations would involve cake formation and dewatering: the most complex would include cake washing and preheating of both feed slurry and wash liquid, together with dewatering of the cake between formation and washing. The problems of counter-current washing are too great to be included in the present paper, but the foundations for its analysis are included here. This paper will aim to show the formulation of these operations in a consistent way and to relate each stage one to another, and demonstrate that filter design can be based on realistic models and simulations of the constituent processes. The principal notation is shown on the diagram in Figure 2.

\section{CAKE FORMATION ON BELT FILTERS}

The working equation for compressible cake filtration is obtained from:

$$
\frac{1}{A} \frac{d V}{d t}=\frac{A \Delta p}{\mu_{f}\left(\alpha_{a v} c V+A R\right)}
$$

by noting the effects of filtration pressure on the specific resistance and porosity of the cake formed, for which the following approximations have been used:

$$
\alpha_{a v}=\alpha_{0} \Delta p^{n}
$$




$$
\varepsilon_{a v}=\varepsilon_{0} \Delta p^{-m}
$$

The equations need to provide the solids throughput rate and a measure of the cake voidage or thickness as related to the form time and the filtrate volume produced. The mass of solids in the cake can be written as:

$$
M_{s}=c V_{f}=\rho_{s}\left(1-\varepsilon_{a v}\right) A L
$$

Combining Eqns. (1) and (4) gives an expression for the rate of growth of the cake:

$$
\frac{d L}{d t}=\frac{c \Delta p}{\mu_{f}\left(1-\varepsilon_{a v}\right) \rho_{s}\left(\alpha_{a v}\left(1-\varepsilon_{a v}\right) \rho_{s} L+R\right)}
$$

which, when integrated at constant pressure between the limits $(0,0)$ and $\left(t_{F}, L\right)$ and rearranged, gives the cake thickness:

$$
L=\frac{1}{\rho_{s}\left(1-\varepsilon_{a v}\right)}\left(-\frac{R}{\alpha_{a v}}+\sqrt{\left(\frac{R}{\alpha_{a v}}\right)^{2}+\frac{2 c \Delta p t_{F}}{\alpha_{a v} \mu_{f}}}\right)
$$

For a belt filter the cake form time is calculated from the belt velocity $\left(v_{B}\right)$ and the length of the form zone $\left(Z_{F}\right)$ :

$$
t_{F}=\frac{Z_{F}}{v_{B}}
$$

and the solids production rate is:

$$
c Q_{f}=v_{B} L h_{B}\left(1-\varepsilon_{a v}\right) \rho_{s}=v_{B} h_{B}\left(-\frac{R}{\alpha_{a v}}+\sqrt{\left(\frac{R}{\alpha_{a v}}\right)^{2}+\frac{2 c \Delta p Z_{F}}{\alpha_{a v} \mu_{f} v_{B}}}\right)
$$

Similar expressions and developments have been used previously ${ }^{1,2}$. The cake form time is also obtained by integration of Eqn. (1); by assuming that the medium resistance is negligible compared with the cake resistance, the form time is alternatively expressed as:

$$
t_{F}=\frac{\alpha_{a v} c \mu_{f}}{2 A^{2} \Delta p} V_{f}^{2}
$$

\section{CAKE DEWATERING}

From the practical point of view calculational procedures must be able to quantify the following three factors:

- The moisture content of the cake passing out of the dewatering zone (this determines the cake saturation at the start of washing or the wetness of the discharged cake) 
- The time taken to reduce the cake moisture to a specified level

- The air flow rate during the dewatering period(s), averaged on the basis of the overall filter cycle (this is the basis for sizing vacuum pumps or compressed air requirements).

The above factors depend upon basic properties of the solid/liquid mixture being separated and upon process operating conditions and their inter-dependencies. In order to effect dewatering a minimum pressure difference must exist across the cake and septum. This is referred to as the threshold pressure and is calculated from:

$p_{b}=\frac{4.6\left(1-\varepsilon_{a v}\right) \sigma}{\varepsilon_{a v} x_{a v}}$

where $x_{a v}$ is the mean size of the particles in the cake and $\sigma$ is the surface tension of the liquid to be removed from the pores of the cake against the gas being used to displace the liquid. When the cake is dewatered over a long period a limiting saturation is approached; further liquid removed by displacement cannot be achieved without a change in the properties of the system. This so called irreducible saturation can be expressed for vacuum or pressure driven dewatering as ${ }^{3}$ :

$S_{\infty}=a_{1}\left(1+a_{2}\left(\frac{\varepsilon_{a v}^{3} x_{a v}^{2}(\rho g L+\Delta p)}{\left(1-\varepsilon_{a v}\right)^{2} L \sigma}\right)\right)^{-a_{3}}$

where $a_{1}, a_{2}$ and $a_{3}$ are constants. For cakes of coarser, granular particle types typical values of these constants are $0.15,0.03$ and 0.49 respectively; the values may differ for other, notably finer, particles in differing solution environments. The above, together with a knowledge of the reduced saturation variations with time, physical properties and process conditions, enable the moisture content to be calculated. The reduced saturation is defined by:

$$
S_{R}=\frac{S-S_{\infty}}{1-S_{\infty}}
$$

$\left(S-S_{\infty}\right)$ is that part of the liquid in the cake which is potentially mobile, and $\left(1-S_{\infty}\right)$ represents the total amount of mobile liquid in the cake ${ }^{4}$. Variations of $S_{R}$ with time are obtained from solutions of coupled force and material balance equations for the simultaneous flow of gas and liquid through the pores of the cake, and are presented as charts ${ }^{5-8}$ with a dimensionless time:

$$
t^{\star}=\frac{p_{b}}{\alpha_{a v} \varepsilon_{a v}\left(1-\varepsilon_{a v}\right) \rho_{s} \mu L^{2}\left(1-S_{\infty}\right)} t
$$

on the abscissa and a dimensionless pressure $\Delta p_{a}{ }^{*}=\Delta p / p_{b}$ as a parameter. The relevant chart for vacuum and pressure dewatering ${ }^{8}$ is reproduced in Figure 3 . Solutions to the same set of equations enable the gas flow rate average over the dewatering time to be calculated, where the dimensionless averaged flow is defined by:

$$
\left(v_{a}^{*}\right)_{a v}=\frac{1}{t^{*}} \int_{0}^{t} \frac{\alpha_{a v} \rho_{s}\left(1-\varepsilon_{a v}\right) \mu_{a} L}{p_{b}} v_{a} d t^{*}
$$


These solutions are plotted on Figure 4, where the dimensionless pressure is again shown as a parameter. Air rates from the derived chart need to be corrected according to the actual pressure appertaining to the proposed equipment and its elevation above sea level. The design chart basis used a dimensionless gas inlet pressure at the cake surface of 100 , and a gas outlet pressure of (100 $-\Delta p_{a^{*}}{ }^{*}$. If it is assumed that the actual gas inlet and outlet dimensionless pressures are $p^{*}{ }_{a e i}$ and $\left(p^{*}{ }_{a e i}\right.$ $-\Delta p_{a}{ }^{*}$ respectively, then the actual dimensionless gas rate through the dewatering section of the filter is:

$$
\left(v_{a e}^{*}\right)_{a v}=\left(v_{a}^{*}\right)_{a v} \frac{100-\Delta p_{a}^{*}}{p_{a e i}^{*}-\Delta p_{a}^{*}}\left(\frac{\left(p_{a e i}^{*}-\Delta p_{a}^{*}\right)^{2}-\left(p_{a e i}^{*}\right)^{2}}{\left(100-\Delta p_{a}^{*}\right)^{2}-100^{2}}\right)
$$

This rate is then corrected to a total filter cycle basis by multiplying it by the ratio of the dewatering to cycle times, for pressure losses through ancillary vessels and/or pipework systems, and finally presented as the rate at pump inlet pressure conditions.

\section{CAKE WASHING}

Washing curves measured on batch systems show two distinct modes of solute removal; an initial stage which represents direct displacement of the retained fluid by the wash liquid, followed by a stage in which the solute concentration falls as a result of a variety of mass transfer processes taking place in the pores of the cake. There is an intermediate stage when some pores are subject to the displacement and others to the mass transfer mechanisms. Although these stages are clear to see from measurements of the instantaneous solute concentrations in the washings from a batch filter, they become indistinct when similar measurements are made on continuous filters. This is due to different parts of the cake (along the length of the belt in the case of a belt filter) finding themselves in different stages of washing, and the washings from all these stages being mixed in the outlet pipework. Hence, whereas the instantaneous solute concentration from a batch filter may be represented by $c$, the output washings from a continuous filter have the concentration $c_{a v}$ which is related to $c$ by $^{9}$ :

$$
\left(c^{*}\right)_{a v}=\frac{c_{a v}-c_{w}}{c_{0}-c_{w}}=\frac{1}{W} \int_{0}^{w} \frac{c-c_{w}}{c_{0}-c_{w}} d W
$$

where $W$ is the number of wash ratios used.

A fundamental theory based on the dispersion model has been developed ${ }^{10}$ to explain how the washing behaviour varies with such factors as cake porosity, saturation and thickness, particle size, wash liquid density and viscosity, and the mass transfer rate of solute through the pore liquids. The dispersion model developed also accounts for back diffusion of solute from the pores into the pool of wash liquid over the cake surface ${ }^{11}$, and when the cake has been dewatered prior to washing, the rate of resaturation ${ }^{12}$. The results for washing a saturated cake on a batch filter are shown on Figure 5 where $c^{*}=\left(c-c_{w}\right) /\left(c_{0}-c_{w}\right)$ and the parameter $D_{n}$ is:

$$
D_{n}=\frac{u L}{D_{L}}=\operatorname{ReSc} \frac{L}{x_{a v}} \frac{D}{D_{L}}
$$

where the axial dispersion coefficient is defined by ${ }^{11}$ : 
$\frac{D_{L}}{D}=0.707+55.5 \mathrm{Pe}^{0.96}$

The product of the Reynolds and Schmidt numbers (i.e. the Peclet number) can be expressed as Re.Sc $=u x_{a v} D$. The idealised dispersion number from Eqn. (17) is affected by several practical factors which occur during filter operation, such as an uneven cake thickness over the filter surface or inhomogeneities in the structure of the cake. The chart proposed previously ${ }^{9}$ to correct $D_{n}$ can be represented by:

$$
\left(D_{n}\right)_{\text {actual }}=0.395+3.22 \log _{10}\left(D_{n}\right)
$$

Dewatering the cake before washing yields complex washing curves ${ }^{12}$ which, after some analysis, can be related to the saturated cake washing curves. Once a required wash ratio is known for a saturated cake, for practical purposes the ratio for an unsaturated cake $W_{S}$ at saturation $S$ can be calculated from:

$$
\frac{W_{S}}{W}=3.6 S_{2}-7.5 S+4.9
$$

The fraction of solute passing into the washing zone which is recovered from the cake by washing, $F$, is calculable from:

$$
F=\int_{0}^{W} c^{*} d W=\left(c^{*}\right)_{a v} W
$$

and the fraction retained in the cake is $(1-F)$. No correction has been allowed to account for wash liquor losses by splashing, run-off etc.

\section{BELT FILTER CYCLE}

The filter belt area is divided into portions for formation, dewatering and washing. The cake form time is related to the pressure difference by Darcy's equation:

$$
\Delta p=\frac{R_{c} \mu_{w}}{A} \frac{V_{w}}{t_{w}}=\frac{\alpha_{a v} c \mu_{w}}{A^{2}} \frac{V_{f} V_{w}}{t_{w}}
$$

noting the relation between cake resistance and specific resistance. The volume of wash liquid used is related to the filtrate volume through the cake liquid hold-up to filtrate volume ratio and the cake saturation $S$ at the start of washing. Noting that the wash ratio for an unsaturated cake is:

$$
W_{S}=\frac{\text { wash liquid flow rate }}{\text { cake liquid flow rate }}=\frac{Q_{w}}{U}=\frac{Q_{w}}{\psi S Q_{f}}
$$

the wash liquid to filtrate volume ratio is: 
$\frac{V_{w}}{V_{f}}=\psi S W_{s}$

and the wash time is:

$t_{w}=\frac{a_{a v} c \mu_{w}}{A^{2} \Delta p} \psi S W_{s} V_{f}^{2}=2 \frac{\mu_{w}}{\mu_{f}} \psi S W_{s} t_{F}$

using Eqn. (9).

In some applications the wash liquid will be removing retained filtrate of a different viscosity, in which case $t_{w}$ is divide Into two parts. The flow rate in the first part, of duration corresponding to the inertial stage of washing, is controlled by the higher viscosity fluid; the flow rate for the remainder of the wash is controlled by the wash liquor viscosity.

For a belt filter the respective areas devoted to each step of the operation are:

$$
\begin{array}{ll}
A_{F}=v_{B} h_{B} t_{F} \quad A_{D 1}=v_{B} h_{B} t_{D 1} \\
A_{w}=v_{B} h_{B} t_{w} \quad A_{D 2}=v_{B} h_{B} t_{D 2}
\end{array}
$$

and

$$
\begin{array}{ll}
t_{F}=Z_{F} / v_{B} & t_{D 1}=Z_{D 1} / v_{B} \\
t_{w}=Z_{W} / v_{B} & t_{D 2}=Z_{D 2} / v_{B}
\end{array}
$$

whilst the total time for the operation is:

$$
t_{t}=\frac{Z}{v_{B}}=t_{F}+t_{D 1}+t_{w}+t_{D 2}=t_{F}\left(1+\frac{t_{D 1}}{t_{F}}+2 \frac{\mu_{w}}{\mu_{f}} \psi S W_{S}+\frac{t_{D 2}}{t_{F}}\right)
$$

from which the fraction of the filter length devoted to cake formation $\left(t_{F} / t_{t}\right)$ is calculable.

\section{SOME ASPECTS OF PROCESS DESIGN}

The above approaches to modelling enable very flexible simulations to be developed to mimic most combinations of formation, dewatering and washing on many different types of filter. Equally, the models allow preliminary sizing and scale-up of equipment, and provide a means of investigating effects of changes in process conditions either at the filter itself or in units upstream of the filter. To show examples of output from such calculations it is assumed that a belt filter is available for a particular application, but details of the modus operandi of the machine are yet to be decided. To enable this a number of 'what if?' questions are asked in the following to illustrate effects of changes in parameters on the equipment performance. The base data used in the following are:

Filter belt width: $\quad 1 \mathrm{~m}$

Filter belt length: $\quad 10 \mathrm{~m}$ Linear velocity of belt: $\quad 0.15 \mathrm{~m} \mathrm{~s}^{-1}$ 


$\begin{array}{ll}\text { Pressure difference: } & 50 \mathrm{kPa} \\ \text { Specific cake resistance: } & 5.2 \times 10^{9} \mathrm{~m} \mathrm{~kg}^{-1} \\ \text { Filter cake porosity: } & 0.729 \\ \text { Effective feed concentration: } & 1127 \mathrm{~kg} \mathrm{~m}^{-3} \\ \text { Density of solids: } & 2350 \mathrm{~kg} \mathrm{~m}^{-3} \\ \text { Density of filtrate: } & 1390 \mathrm{~kg} \mathrm{~m}^{-3} \\ \text { Viscosity of filtrate: } & 10^{-3} \mathrm{~Pa} \mathrm{~s} \\ \text { Mean particle size: } & 8 \mu \mathrm{m} \\ \text { Barometric pressure: } & 101.3 \mathrm{kPa} \\ \text { Filtrate-gas surface tension: } & 0.07 \mathrm{~N} \mathrm{~m}^{-1} \\ \text { Gas viscosity: } & 1.81 \times 10^{-5} \mathrm{~Pa} \mathrm{~s} \\ \text { Wash liquid viscosity: } & 10^{-3} \mathrm{~Pa} \mathrm{~s}^{-1} \\ \text { Solute diffusivity: } & 10^{-9} \mathrm{~m}^{2} \mathrm{~s}^{-1} \\ \text { Density of wash liquid: } & 10^{3} \mathrm{~kg} \mathrm{~m}^{-3} \\ t_{D 1}=0.5 t_{F} & \\ t_{D 2}=0.5 t_{F} & \end{array}$

The wash ratio is varied from zero (no washing) to 2.5 based on a saturated cake, thereby changing the periods apportioned to each stage of the cycle. Many of the above parameters are varied systematically to show their effects on the total cycle. Cost and value data are not used here, but could clearly be included in the analysis so that an economic optimum for the operation could be sought.

\section{Effects of Belt Speed}

Changing the speed of the belt alters the time available to accomplish each operation in the cycle, as shown in Figure 6. Reducing the belt speed allows formation of a thicker cake, the resistance of which reduces the air flux based on the total cycle. When wash ratios greater than 0.5 are used (which is normally the case) the slight improvement in washing effectiveness as the cake thickness increases can be seen (the fractional recovery of solute rises with cake thickness). The discharged cake moisture content increases slightly as belt speed is reduced, due to the increasing cake thickness. Higher belt speeds enable greater solids production rates by the formation of thinner cakes; this may not be desirable if a high washing efficiency is also required, in which case economic criteria may need to be adopted. Additionally, this may have implications for the life expectancy of filter belts and media.

\section{Effects of Pressure Difference}

The curves in Figure 7 show the effect of changing the pressure difference from $25 \mathrm{kPa}$ to $75 \mathrm{kPa}$, when the same vacuum is applied over all stages of the cycle. In these calculations the cake formed is assumed to be compressible and the constants in Eqn. (2) and (3) are taken to be $\alpha_{0}=7.1 \times 10^{8} \mathrm{~m}$ $\mathrm{kg}^{-1}, n=0.51, \varepsilon_{0}=0.9$ and $m=0.054$ when $\Delta p$ is in $\mathrm{kPa}$.

The impact of increasing pressure difference (over this small range) on solids production rate is small in comparison with its effects on dewatering, where higher gas flows and lower cake moisture contents can be obtained. In the case of an incompressible filter cake whose structure does not change during washing, the effects of pressure are solely to alter wash liquid flow rates according to Darcy's law since cake thickness effects are minimal over this range of pressures.

\section{Effect of Barometric Pressure (or Altitude of Plant)}


Barometric pressure affects the required capacity of the vacuum pump, as shown in Figure 8 . The variation of barometric pressure with altitude used was that recommended by DIN $4705^{13}$, and the applied pressure difference was constant at $50 \mathrm{kPa}$. No other effects on the filter cycle were found from the calculations.

\section{Effects of Temperature}

The effects of temperature on filter performance are complex in so far as physical properties which influence all parts of the cycle are affected. Temperature affects the rates of liquid flow in all parts of the cycle through the fluid viscosities, the moisture contents obtained at the end of each dewatering period through surface tensions (effects through fluid densities are insignificant), and the moisture content at the end of the first dewater influences cake washing. The property values used over the 5$35^{\circ} \mathrm{C}$ range are shown in Table 1, where filtrate values are typical of an alcohol and wash liquid values are typical of wafer.

In Figure 9 the cake thickness is shown to increase as the feed temperature is increased, due to the filtrate viscosity reduction. Although the diagram shows a simultaneously reducing total air flow rate this conceals the fact that the air is not necessarily consumed equally by the two dewatering stages because of the differing filtrate and wash properties. For the same reason the cake may be drier after the first dewater than it is at discharge.

Increasing the wash liquid temperature rather than that of the feed slurry causes a reversal of the effects of temperature on air consumption and discharged cake moisture contents, Figure 10. The cake thickness changes are due to the constraints that a fixed length of belt running at a constant speed has been used as a basis for the calculations, and altering the wash ratio causes different times to be allowed for cake formation.

Preheating both slurry and wash feed does not automatically lead to better washed or drier cakes; this can be seen by comparing Figure 11 with Figures 9 and 10. Air consumption tends to be reduced but the moisture content of discharged cakes can be increased. To determine the precise effects of these pre-treatment operations each new application with the correct physical properties must be analysed separately.

\section{Effects of Particle Size}

In many processing sequences the filter is preceded by a particle formation unit such as a crystalliser or precipitator, the product from which can have a profound effect on the filter performance. It is therefore pertinent to be able to quantify the likely influences of changes in the operation of the crystalliser or precipitator on the filter. The effects of particle size on the washing and dewatering are stated explicitly in the equations and charts, and in the case of cake formation the primary (but not necessarily only) effect in the 4-32 $\mu \mathrm{m}$ size range is on the specific cake resistance:

$$
\alpha_{a v} \propto \frac{1}{x_{a v}^{2}}
$$

i.e. the specific resistance increases inversely as the square of the mean particle size. Hence the effects of particle size can be summarised as in Figure 12.

Unless the cake is compressible, which is not assumed here, the porosity is independent of particle size when the feed size distributions have similar shapes and the ratio of the maximum to minimum 
sizes are the same. Under such circumstances larger particles would be expected to increase the thickness and bulk volume of the cake, as shown in Figure 12. With the thicker cakes, slightly more effective washing is achieved at higher wash ratios (this is also influenced by the saturation reached at the end of the first dewater), larger air volumes are consumed (because of the greater permeability of the cake), and a marginally lower cake moisture is achieved at discharge.

\section{CONCLUDING REMARKS}

The approach outlined in this paper points a way to filter design and scale-up which takes some account of the effects of physical properties and operating conditions. The models used are based on fundamental concepts of varying complexity, all of which are sufficiently well developed to facilitate design calculations. The models can also be incorporated easily into process integration and optimisation packages; they form a small part of a suite of computer software packages for solid/liquid separation equipment selection and design being developed at the University of Exeter. More complex models based on more fundamental principles may be used in the simulations, with advantage in some instances, but these require additional validation and research before being relied upon. Applications of such approaches could prevent the implementation of equipment whose actual performance subsequently falls below anticipated operating demands, and certainly enable the user engineer to carry out independent checks on equipment manufacturers design and performance claims.

It is hoped that this paper will be useful to the non-specialist engineer, to whom recent developments in the understanding of the filter cycle probably appear fragmented and often unrelated. It is not the detailed results presented in this paper which are important (although they may be of considerable interest to some), but it is the underlying methodology used to obtain the results which has widespread implications.

\section{NOMENCLATURE}

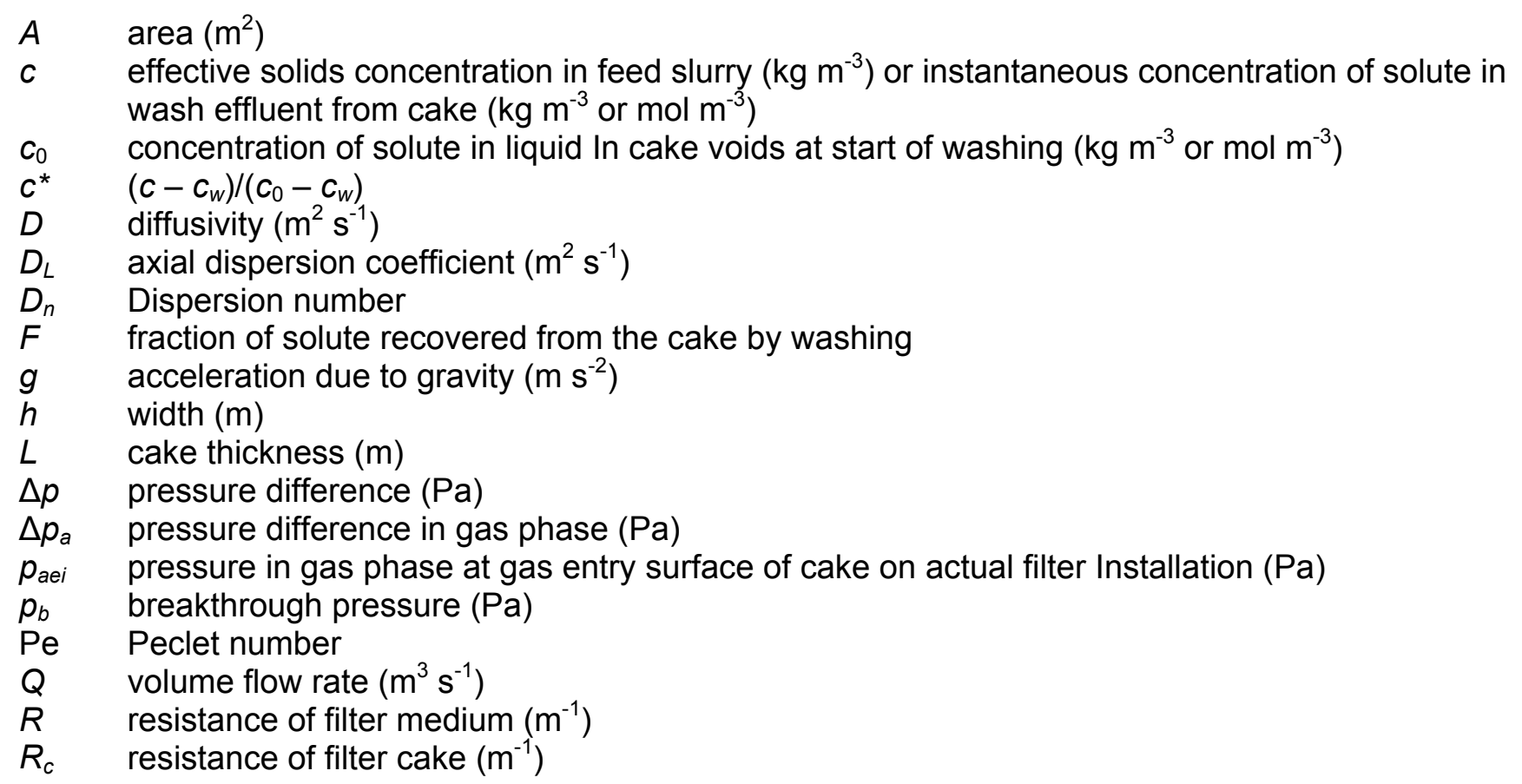




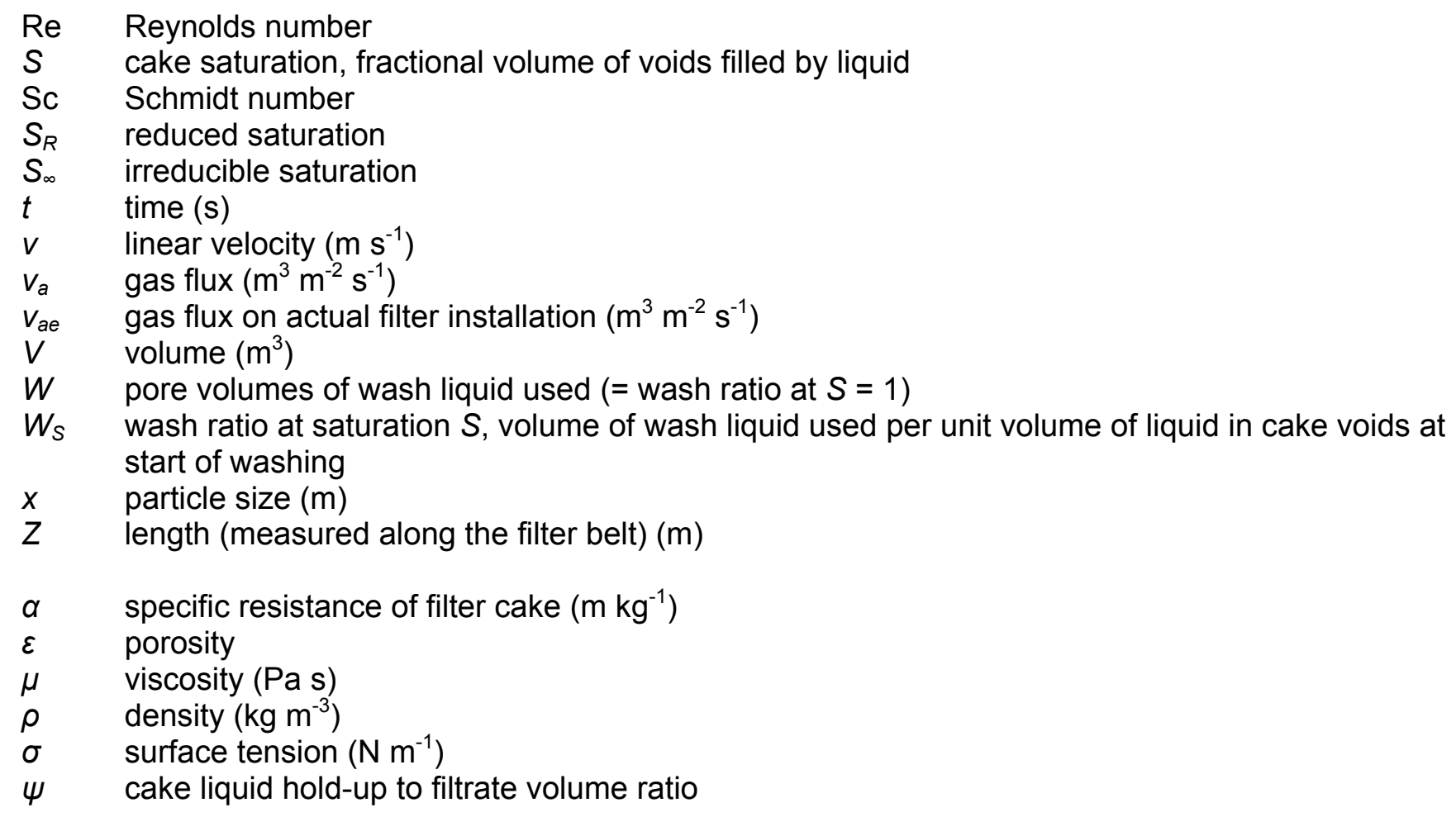

\section{Subscripts}

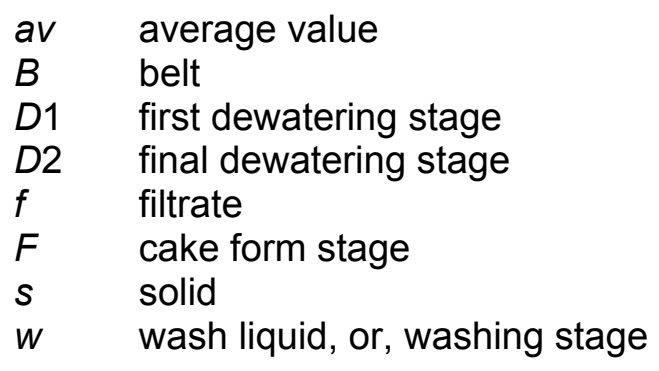

Superscripts

denotes a dimensionless variable

\section{REFERENCES}

1. Hermia J. and Mullier Ph., Proc. SBF Conf. 'Economic optimisation strategy in solid/liquid separation processes, pp.177, Louvain-la-Neuve, Belgium, 1981.

2. Leclerc D., Publ. Ref. 78/135/AD/05/F, CPIC-ENSIC, Nancy.

3. Wakeman R.J., Int. J. Miner. Process., 3, 193, 1976.

4. Wakeman R.J., Int. J. Miner. Process., 5, 379, 1979.

5. Wakeman R.J., Filtration and Separation, 16, 655, 1979. 
6. Wakeman R.J. and Vince A., Chem. Eng. Res. Des., 64, 94, 1986.

7. Wakeman R.J. and Vince A., Chem. Eng. Res. Des., 64, 104, 1986.

8. Purchas D.B. and Wakeman R.J., Solid/Liquid Separation Equipment Scale-up, pp.701-744, Uplands Press, London, 1986.

9. Wakeman R.J., 1980, Filtration and Separation, 17, 67, 1980.

10. Wakeman R.J., Chem. Eng. Res. Des., 64, 308, 1986.

11. Wakeman R.J. and Attwood G., Filtration and Separation, 25, 272, 1988.

12. Wakeman R.J. and Attwood G., Chem. Eng. Res. Des., 68, 161, 1990.

13. DIN4705 Parts 1 \& 2, Calculation of Inside Dimension of Chimneys, 1979. 


\section{FIGURES AND TABLES}

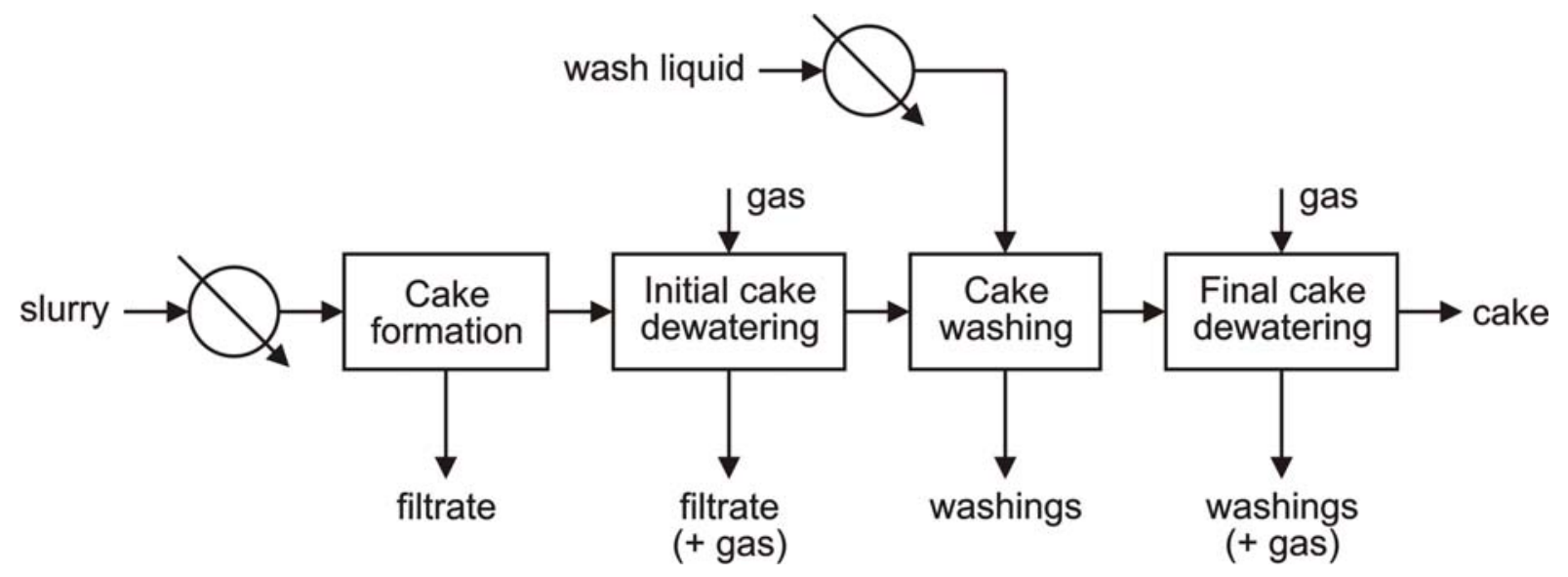

Figure 1: Possible sequences of filter operations.

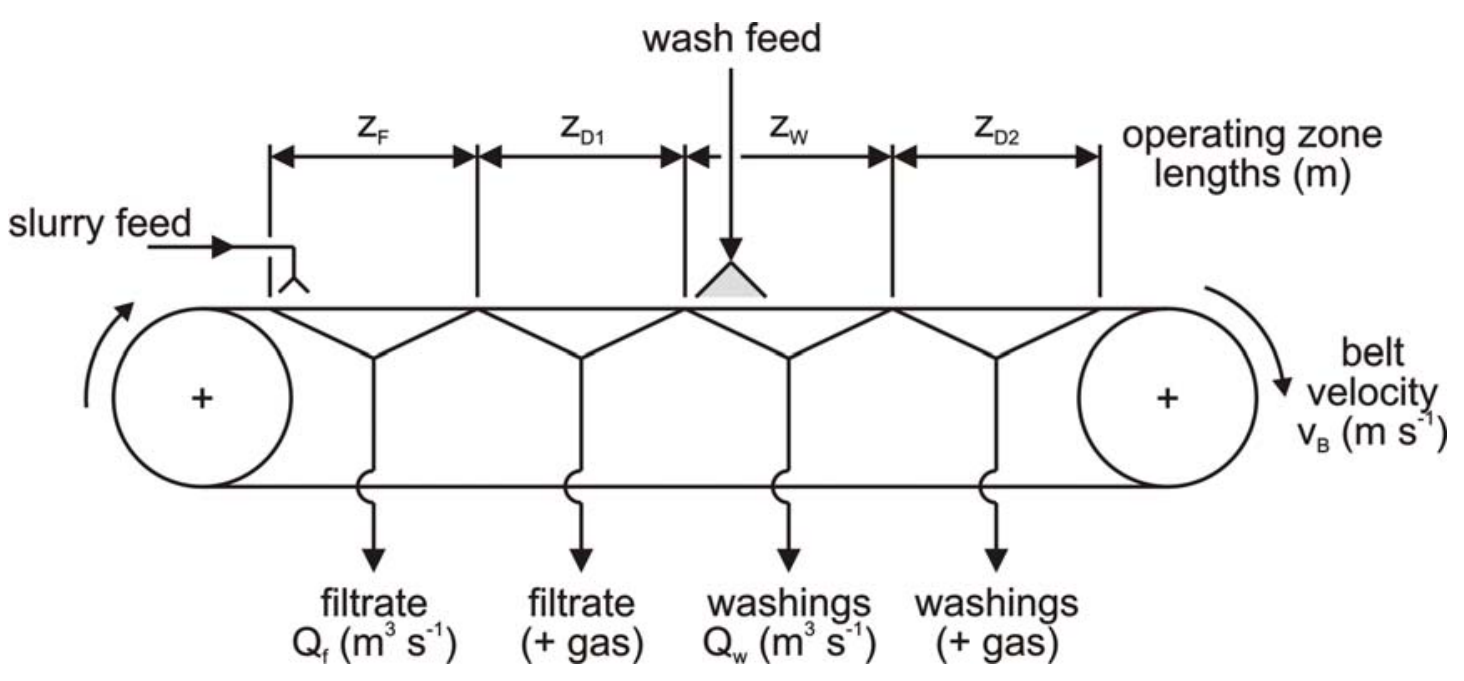

Figure 2: Filter belt notation. 


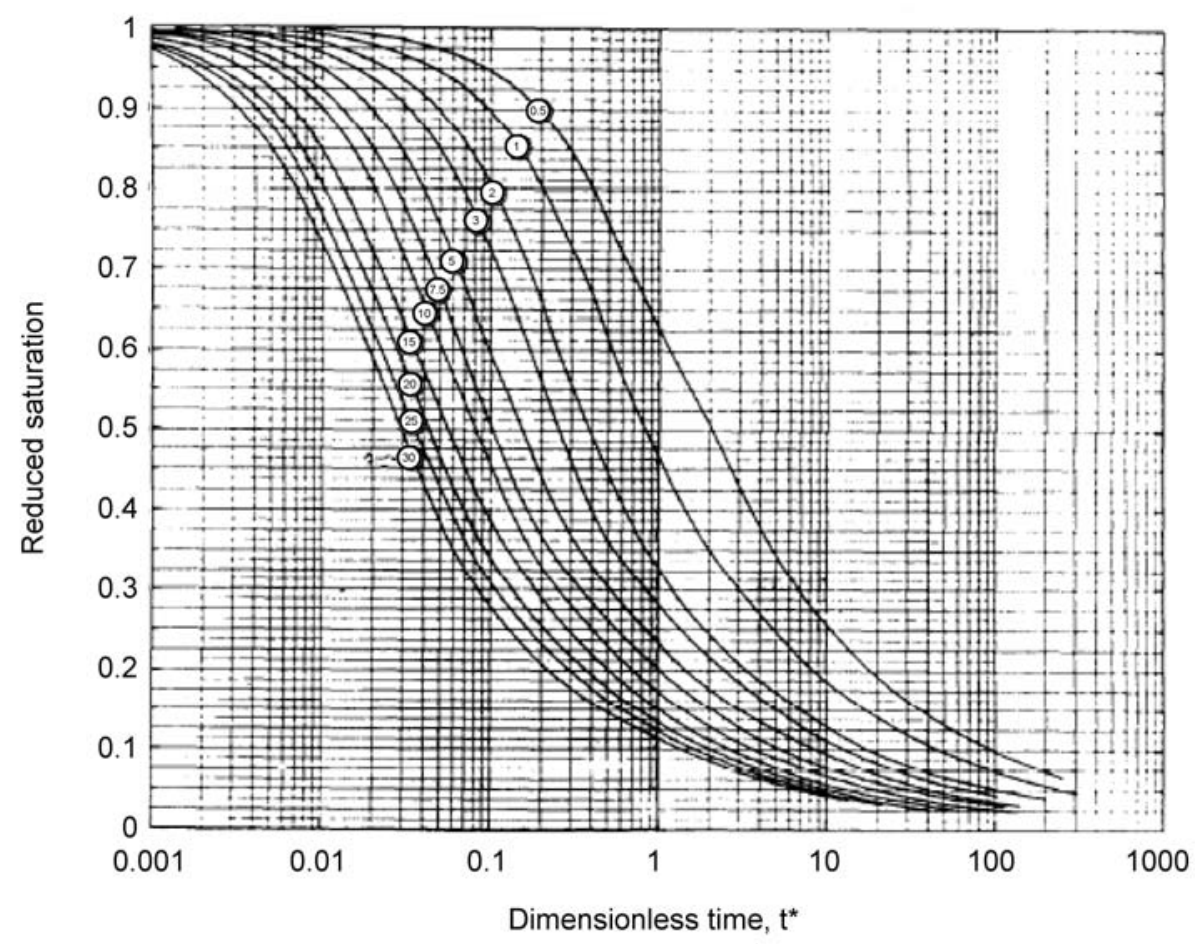

Figure 3: Cake reduced saturation vs. dimensionless time. 


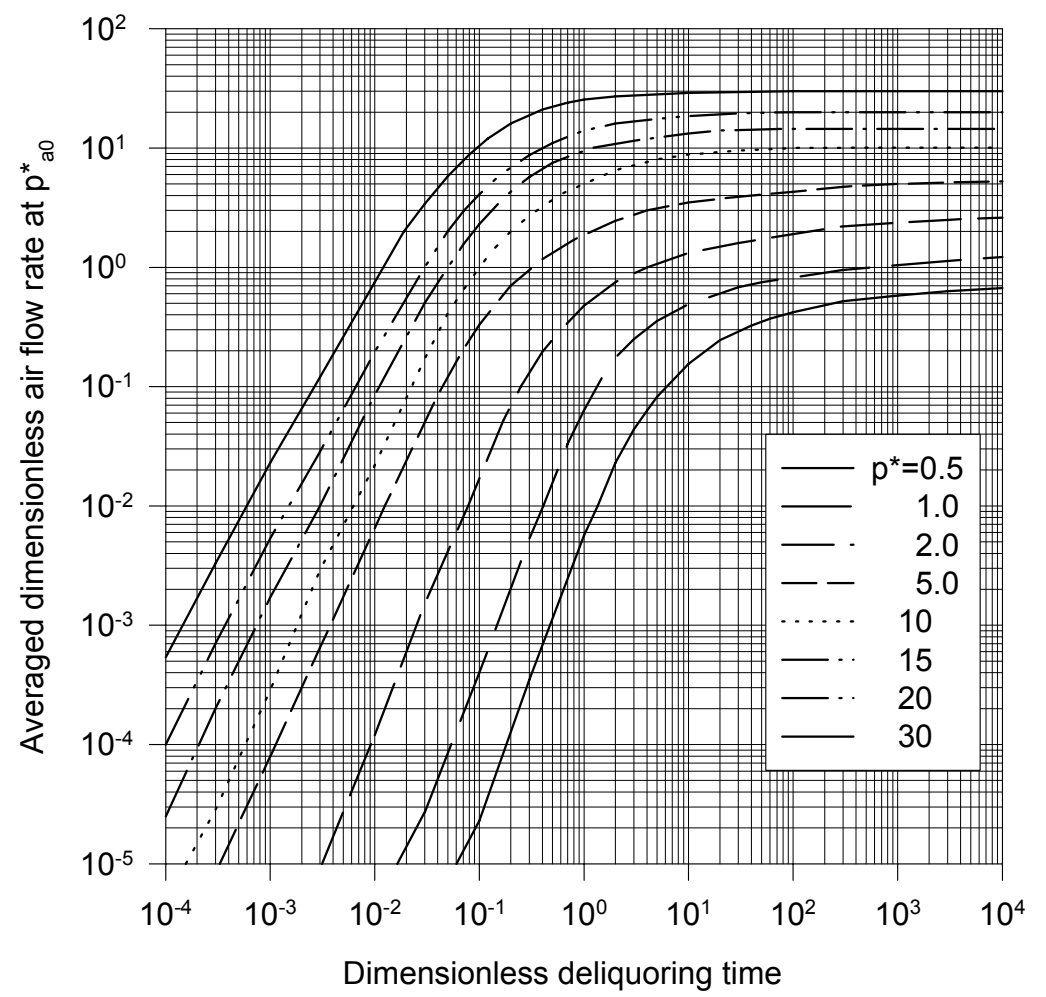

Figure 4: Mean gas flow rate to time $t^{*}$ vs. $t^{*}$.

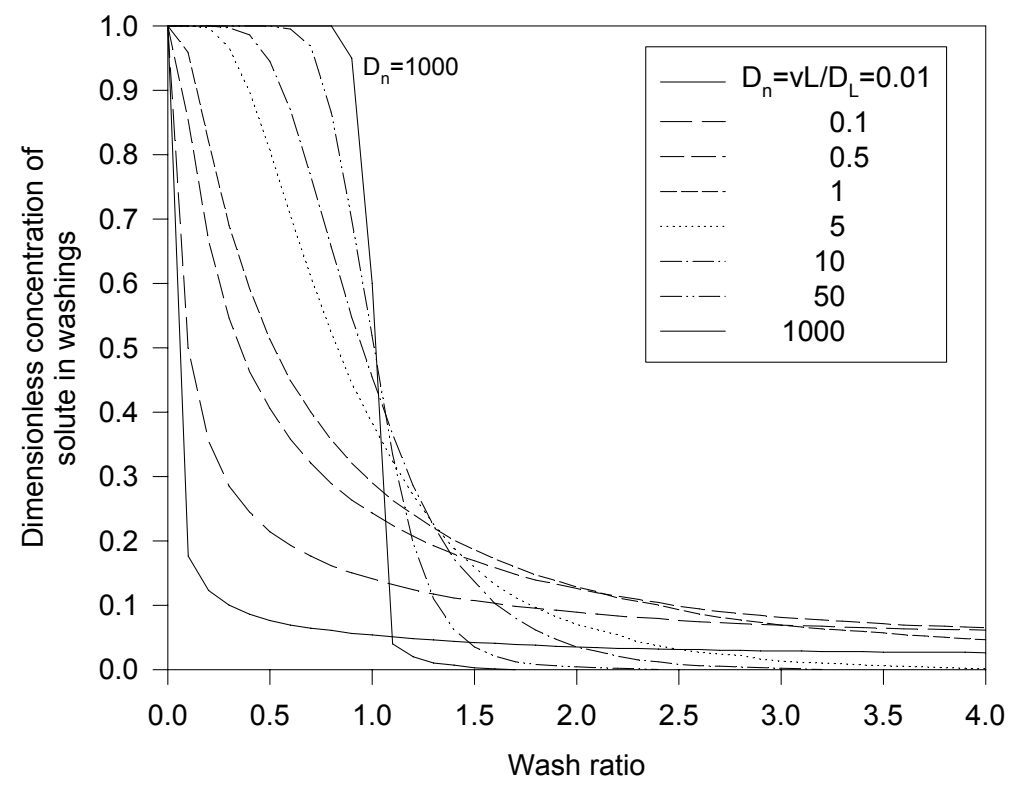

Figure 5: Batch washing curves for a saturated cake (c* vs. W). 

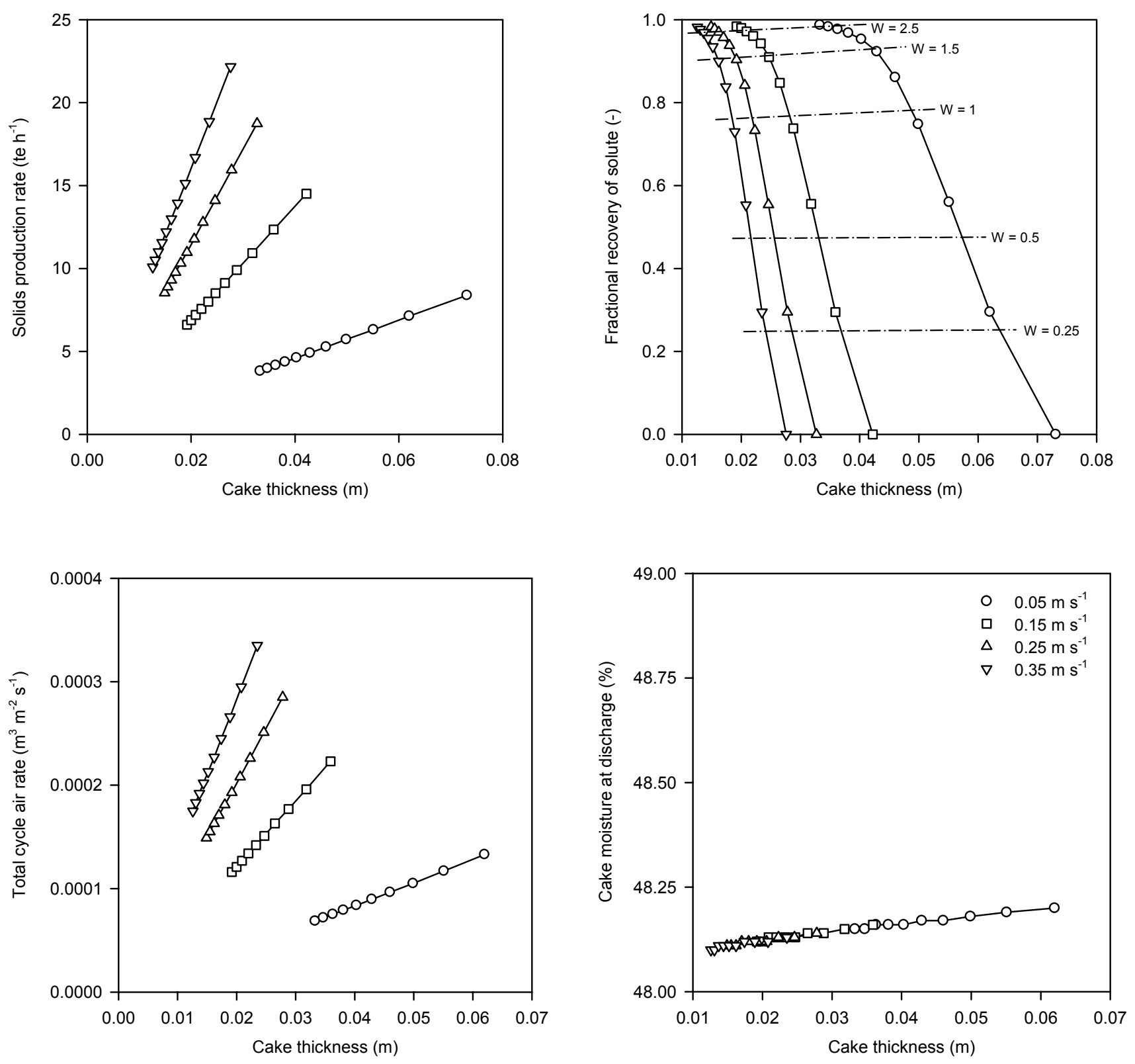

Figure 6: Effects of belt speed on filter performance. 

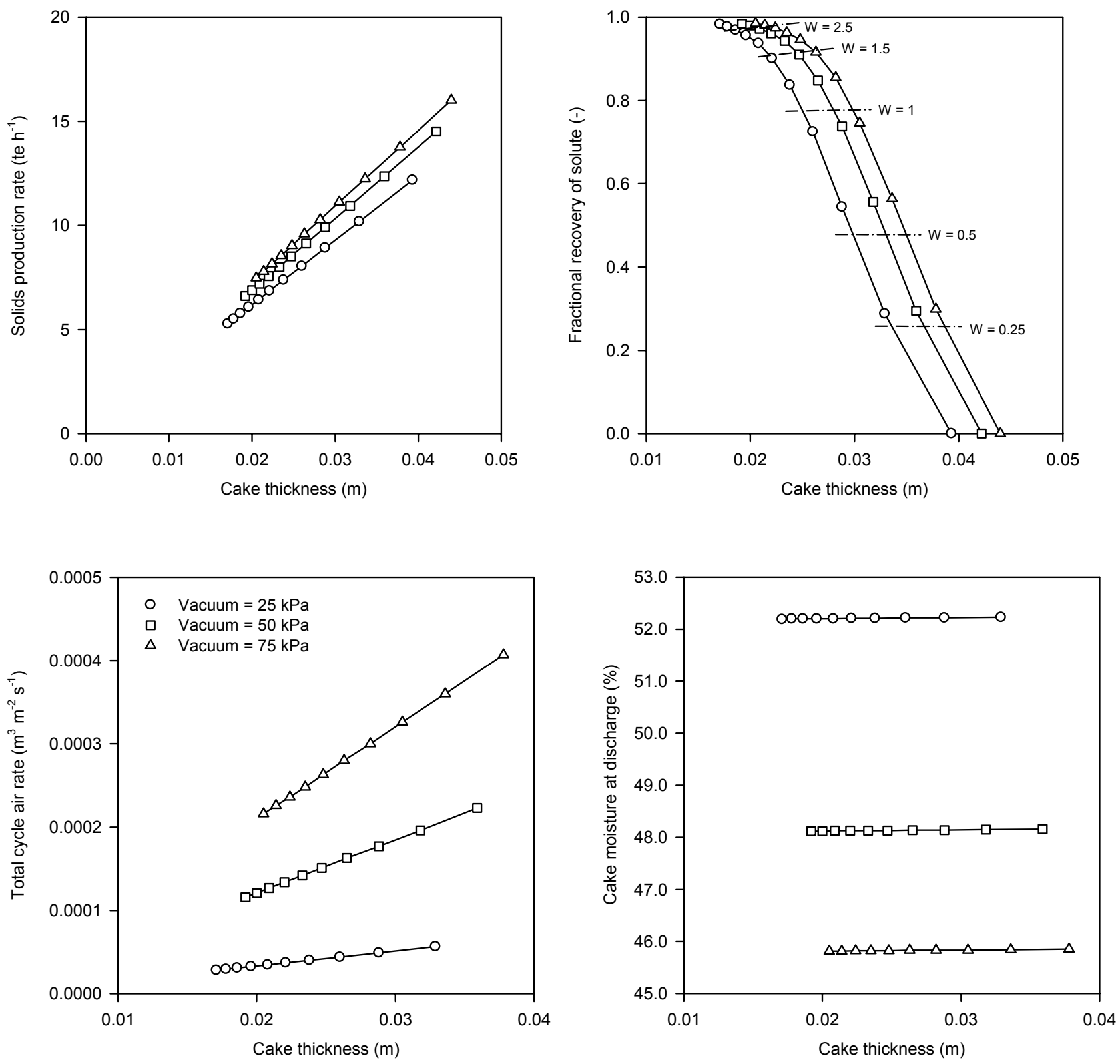

Figure 7: Effects of pressure difference on filter performance. 


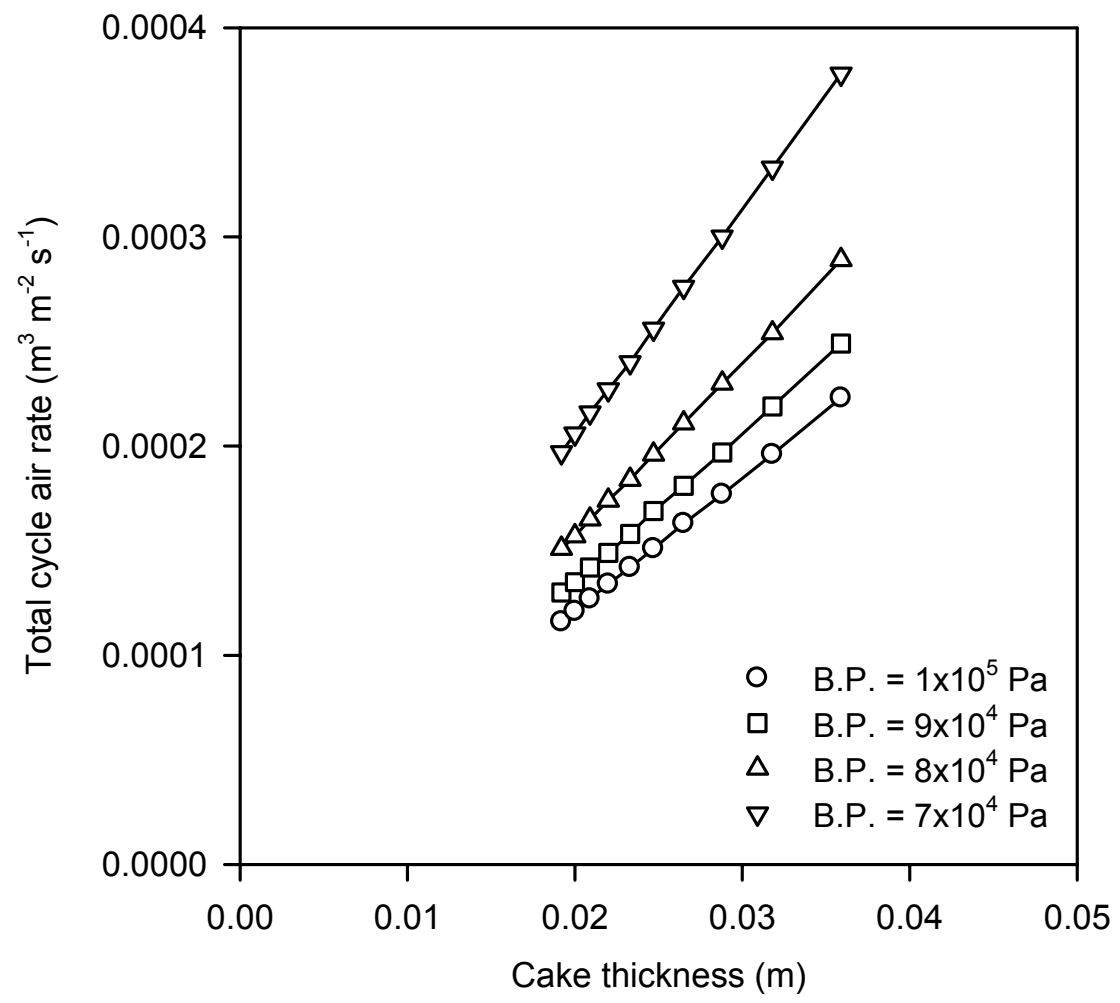

Figure 8: Effect of barometric pressure on gas rates. 

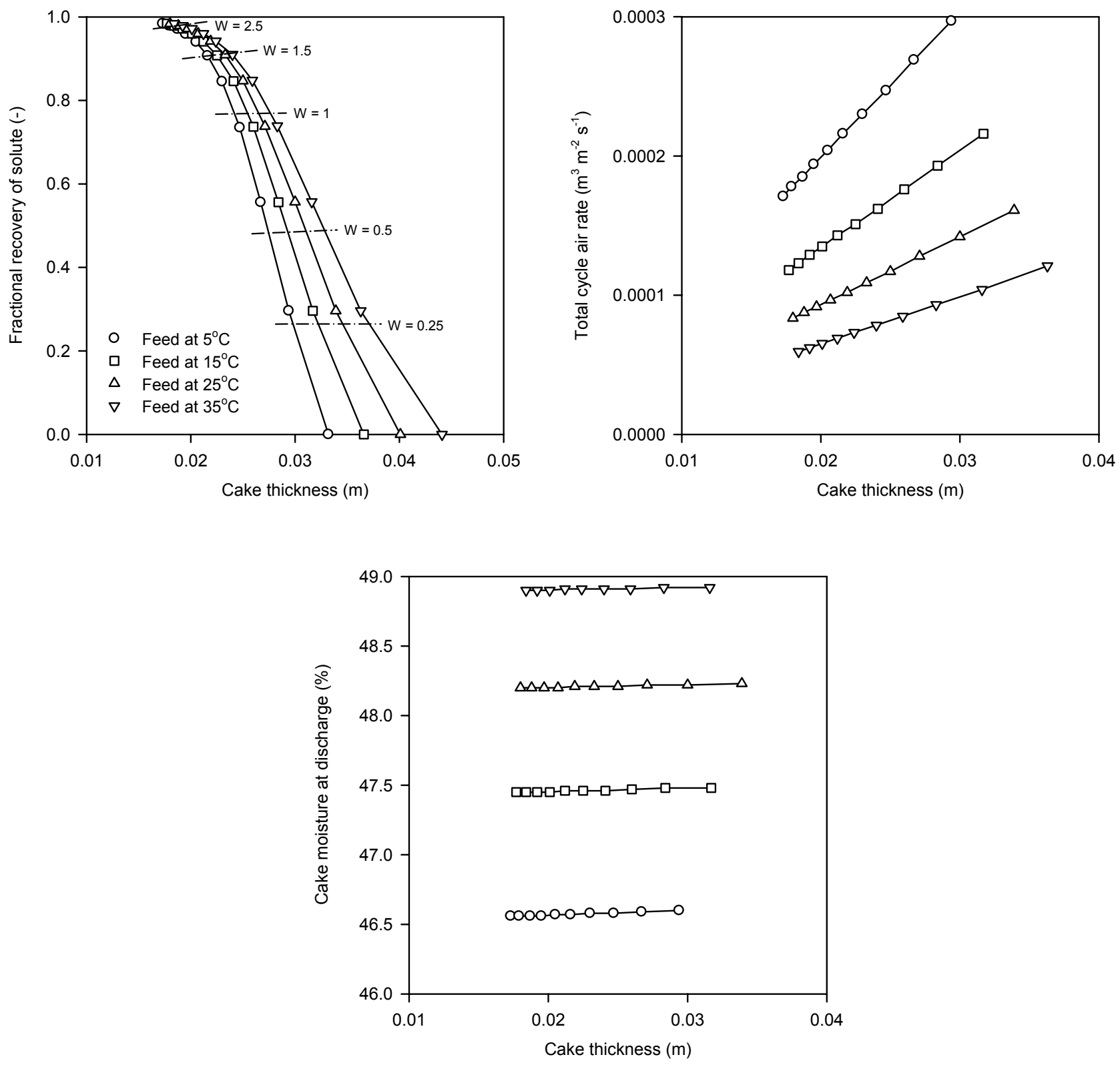

Figure 9: Effect of feed temperature on filter performance (wash liquid temperature $15^{\circ} \mathrm{C}$ ). 

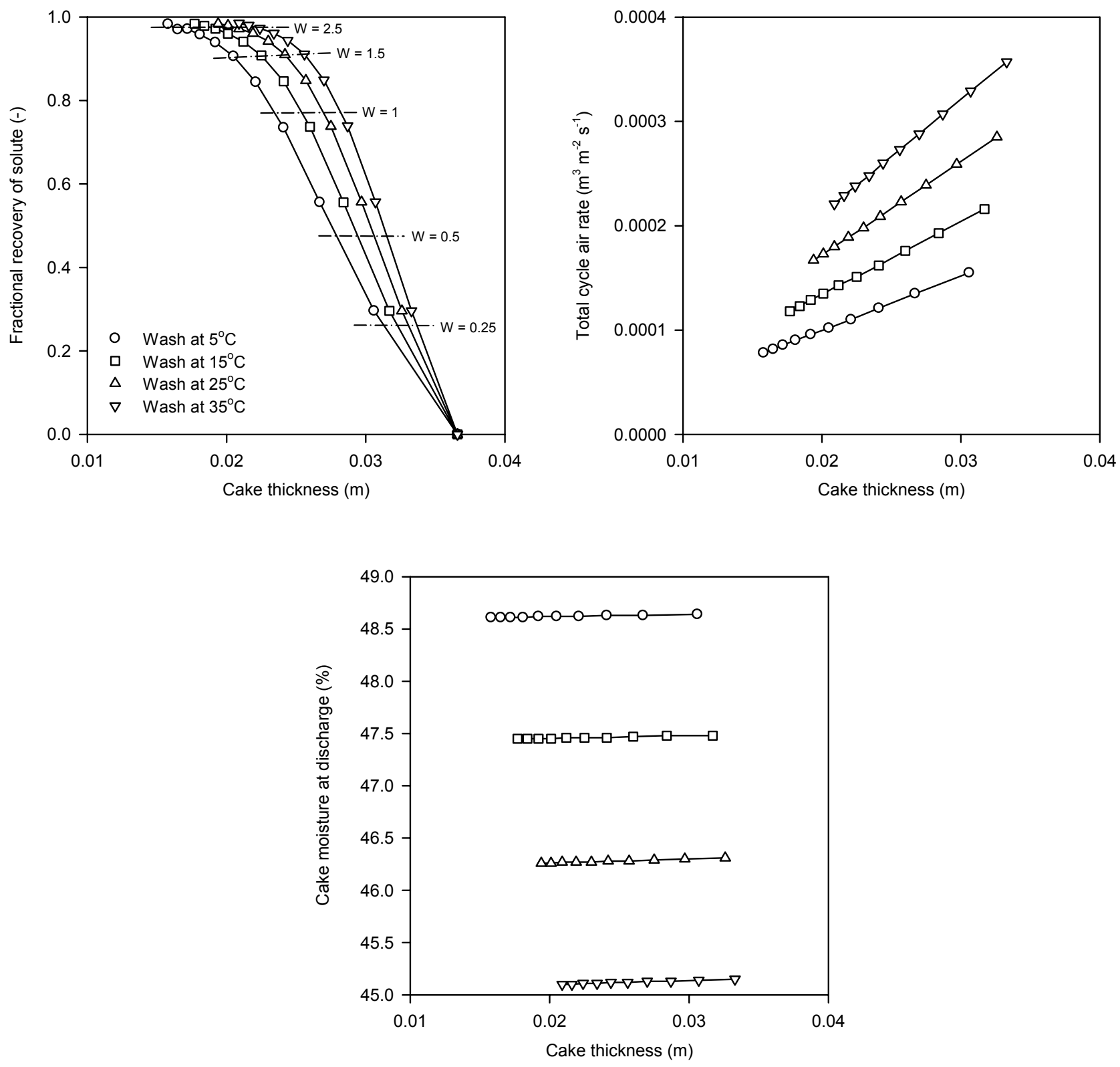

Figure 10: Effect of wash liquid temperature on filter performance (feed slurry temperature $15^{\circ} \mathrm{C}$ ). 

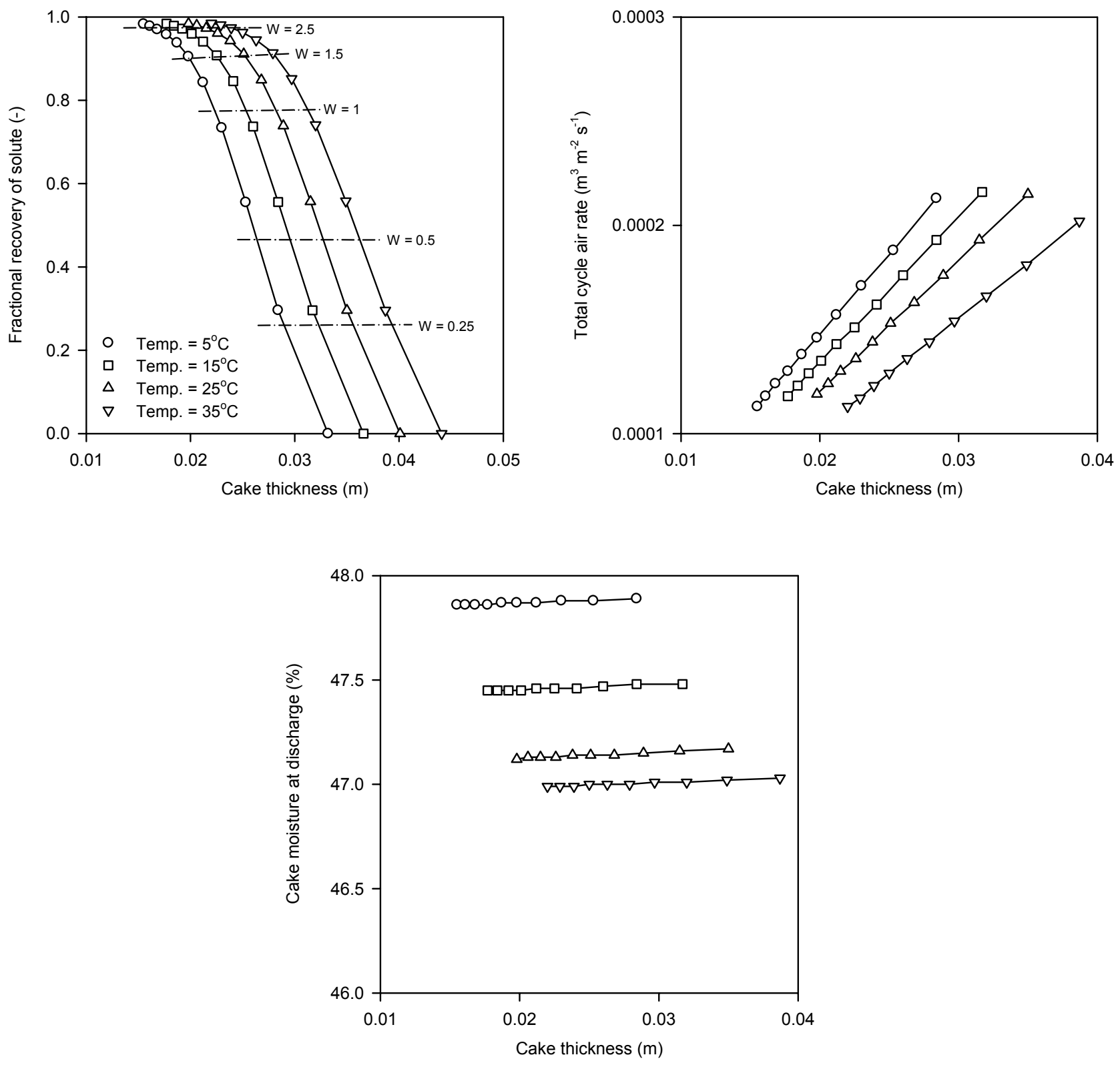

Figure 11: Effects of pre-heating slurry and wash feeds. 

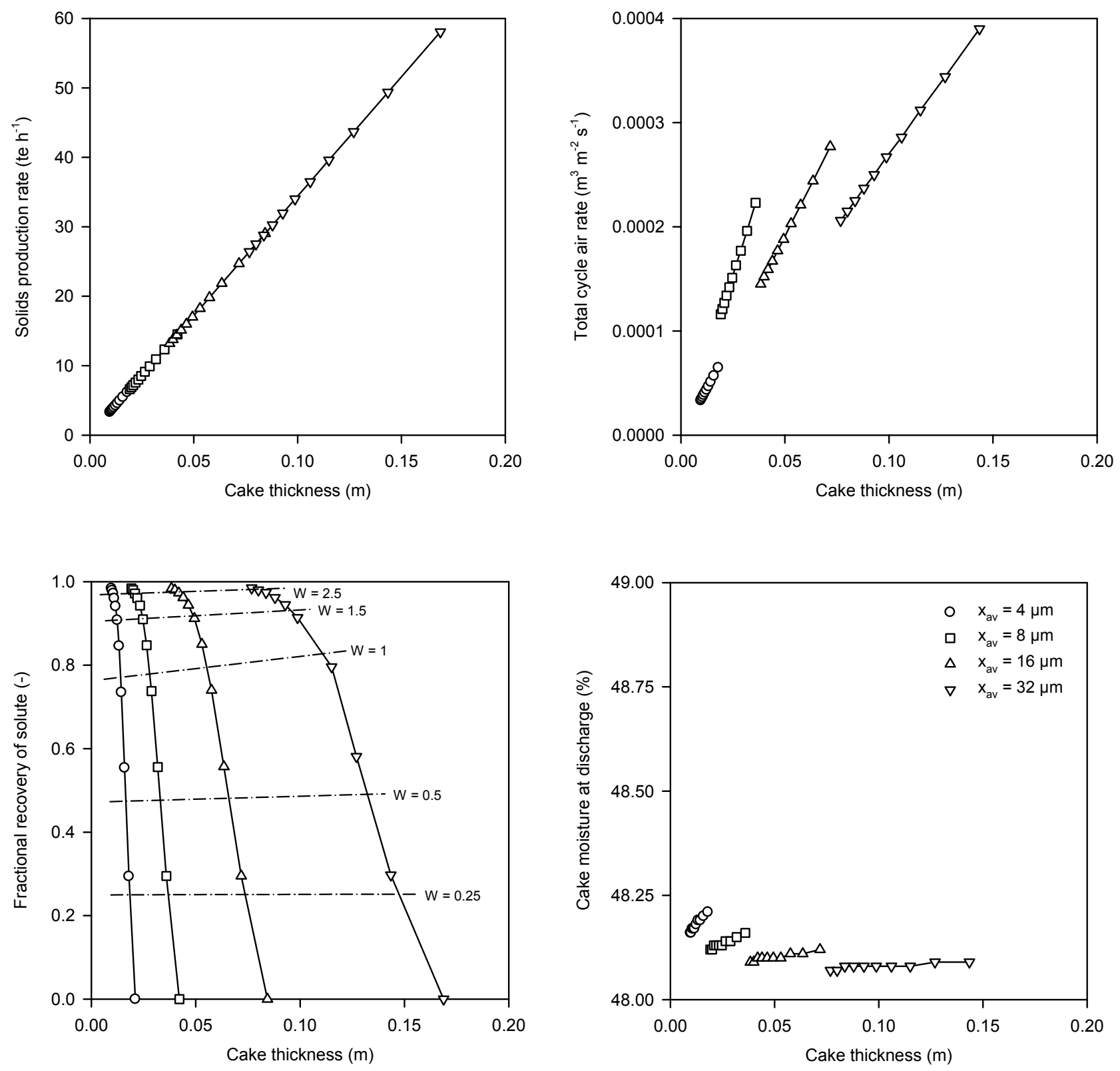

Figure 12: Effects of particle size on filter performance. 


\begin{tabular}{|c|c|c|c|c|c|c|}
\hline Temperature $\left({ }^{\circ} \mathrm{C}\right)$ & \multicolumn{3}{|c|}{ Filtrate } & \multicolumn{3}{c|}{ Wash liquid } \\
\cline { 2 - 6 } & $\mu_{f}(\mathrm{~Pa} \mathrm{~s})$ & $\rho_{f}\left(\mathrm{~kg} \mathrm{~m}^{-3}\right)$ & $\sigma_{f}\left(\mathrm{~N} \mathrm{~m}^{-1}\right)$ & $\mu_{w}(\mathrm{~Pa} \mathrm{~s})$ & $\rho_{w}\left(\mathrm{~kg} \mathrm{~m}^{-3}\right)$ & $\sigma_{w}\left(\mathrm{~N} \mathrm{~m}^{-1}\right)$ \\
\hline 5 & 0.00162 & 803 & 0.0238 & 0.00152 & 1000 & 0.0749 \\
15 & 0.00133 & 794 & 0.0232 & 0.00114 & 999 & 0.0735 \\
25 & 0.0011 & 785 & 0.0223 & 0.00089 & 997 & 0.072 \\
35 & 0.00091 & 777 & 0.0213 & 0.00072 & 995 & 0.0703 \\
\hline
\end{tabular}

Table 1: Variations of fluid properties with temperature. 